\title{
Analysis of Spatiotemporal Dynamics of Virus Spread in an Australian Hop Garden by Stochastic Modeling
}

Sarah J. Pethybridge, Tasmanian Institute of Agricultural Research, University of Tasmania, P.O. Box 447, Burnie, Tasmania, 7320, Australia; and L. V. Madden, Department of Plant Pathology, The Ohio State University, Ohio Agricultural Research and Development Center, Wooster 44691-4096

\begin{abstract}
Pethybridge, S. J., and Madden, L. V. 2003. Analysis of spatiotemporal dynamics of virus spread in an Australian hop garden by stochastic modeling. Plant Dis. 87:56-62.

The dynamics of spread of Hop latent virus (HpLV), Hop mosaic virus (HpMV), and Apple mosaic virus (ApMV) in an Australian hop garden were characterized by fitting a stochastic spatiotemporal model, using the Monte Carlo Markov Chain (MCMC) method, to the changes in patterns of virus-infected plants. The model has parameters for background infection rate (from virus reservoirs outside the gardens) and local infection rate (spread from infected plants to virus-free plants). The HpLV epidemic could be explained by very short range spread within the garden, suggesting mechanical transmission through cultural operations. This is consistent with the absence of the only known aphid vector of HpLV from Australia. The HpMV epidemic could be explained by local spread coupled with background infection. This suggests that HpMV may be introduced by aphids, and subsequent localized spread may occur by aphids or mechanical means. The ApMV epidemic was also consistent with localized spread coupled with background infection, but the possibility of longer-range spread could not be rejected for this virus. Although intra-garden transmission of ApMV may occur through contact or cultural operations, these results suggest that other mechanisms could contribute to transmission of ApMV in Australian hop gardens. Join-count statistics for the patterns of infected plants supported the conclusion from the spatiotemporal modeling that short-range spread was the primary determinant of disease increase.
\end{abstract}

Additional keywords: Humulus lupulus

Hops (Humulus lupulus L.; Family Cannabidaceae) are grown on approximately 600 ha in two states of Australia, Victoria and Tasmania. The industry supplies the majority of the domestic market, while $88 \%$ of the crop is exported to Europe, Asia, and North America. A number of important hop diseases, including powdery mildew (Sphaerotheca macularis (Wallr.:Fr.) Lind)), downy mildew (Pseudoperonospora humuli ((Miyabe \& Takah.) G.W. Wils.), and Hop stunt viroid are absent from Australia. The three most important plant pathogens found commonly occurring in Australian hop gardens are Hop latent virus ( $\mathrm{HpLV})$ and Hop mosaic virus (HpMV), members of the genus Carlavirus, and Apple mosaic virus (hop [ApMV$\mathrm{H}$ ] and intermediate [ApMV-I] serotypes), an Ilarvirus (26,33). On the basis of recent studies of variation in the coat protein gene from ilarvirus isolates from Australian hop gardens, we designate ApMV-H and ApMV-I to refer to what was previously

Corresponding author: S. J. Pethybridge

E-mail: sarah_jp@utas.edu.au

Accepted for publication 25 August 2002.

Publication no. D-2002-1118-03R

(C) 2003 The American Phytopathological Society called Prunus necrotic ringspot virus, apple (PNRSV-A) and intermediate (PNRSVI) serotypes (5), respectively (D. Crowle, S. J. Pethybridge, and C. R. Wilson, unpublished data). The introduction of these viruses to Australia probably occurred through vegetatively propagated clonal hop breeding material from countries such as the United States, Europe, and the United Kingdom (UK). The importance of these viruses to Australian hop production depends upon the rate of reinfection after planting with virus-free material (33) and the effect of these viruses and their various combinations on cone yield and levels of brewing organic acids. The magnitude of yield loss attributed to viral infection can be related to virus strain, environmental conditions, and the tolerance of the cultivar affected (32).

Phorodon humuli (Schrank) $(1,10,29)$ has been demonstrated to be the most efficient aphid vector of HpLV and HpMV, but it is not present in Australia. Two other aphid species, Macrosiphum euphorbiae (Thomas) and Myzus persicae (Sulzer), which are present in Australia, have been demonstrated to be important in the spread of HpMV (2,3). No alternative aphid vector of HpLV has been identified, and the absence of $P$. humuli in Australia (27) and New Zealand (22) has been suggested to be responsible for slower rates of carlavirus spread (27). In areas where $P$. humuli is ubiquitous, the spatial pattern of carlavirus spread indicates strong edge effects and steep infection gradients reflecting the use of Prunus spp. as a winter host $(4,7)$. However, the spatial patterns of carlavirusinfected plants in Australian hop gardens (in the absence of $P$. humuli) were strongly influenced by plant contact. This was suggestive of either mechanical transmission (through cultural operations such as harvesting, spraying, or slashing of superfluous, untrained basal shoots), or movement of apterous or alatae aphid vectors through "bridges" formed between plants through plant contact (30).

Very little is known about the natural infection of Malus spp. trees by ApMV. However, it is likely to be similar to that of the related virus, PNRSV. The spread of PNRSV between Prunus spp. trees has been consistently associated with the presence of virus-infected pollen $(6,9,13,14)$ and the mechanical transmission elicited through the feeding habits of thrips $(19,20)$. In hop, investigations of plant-toplant spread by vectors have examined the nematode Longidorus macrosoma (12) and the mite Vasates fockeui (34). Although in some hop cultivars in the UK up to $51 \%$ of seeds were infected by ApMV (36), the role of seed and pollen transmission in hop gardens has been considered unimportant because virus spread occurs in the absence of male plants, the virus can be transmitted to female hop plants, and the shift to seedless hop gardens has not been associated with significant decreases in the rate of ilarvirus reinfection after establishing new gardens with virus-free material. Analyses of the spatial patterns of ApMV-infected hop plants in the UK (38) and Australia (31) have suggested that infected plants are more likely to be autocorrelated along rows, a pattern not reminiscent of the involvement of pollen. Despite the relatively high lability of ApMV in undiluted sap, mechanical transmission of ApMV has been considered to be the most likely means of transmission (39). Further trials in the glasshouse and field in Europe (11) and Australia (30) have suggested similar conclusions.

Most studies of virus-infected plants, including virus-infected Australian hops (31), have characterized spatial patterns using: (i) "point pattern" methods (e.g., counts per sampling unit, distance between 
infected plants) and associated indices and distributional parameters; and (ii) geostatistical methods that quantify the covariance of disease among sampling units using correlation coefficients or similar statistics $(23,24)$. When these methods are used together, a detailed characterization of the spatial pattern of disease can be obtained (25), although neither class of method can directly or adequately depict disease development in terms of classical population-dynamic processes. Recently, Gibson and colleagues developed an innovative approach to model complex spatiotemporal disease dynamics and to analyze observed patterns of disease in the field (15-17) by estimating parameters of a stochastic model. Through this modeling and analysis approach, one represents the increase in diseased plants through component terms (parameters) for the spread from plant to plant and for infections unrelated to the position of other diseased plants. The analysis requires spatial information on the position of diseased (and disease-free) plants at two or more times during an epidemic.

The primary objective of this study was to examine the spatiotemporal development of HpLV-, HpMV-, and ApMVinfected plants in an Australian hop garden using the analytical stochastic modeling approach of Gibson $(15,16)$. We use the results of the analysis to elucidate, probabilistically, the relative importance of disease spread from infected plants (contagion) and from inoculum reservoirs outside the gardens. As a secondary objective, we calculate join-count statistics (a form of geostatistics for binary data; 40) for these same data sets in order to determine the extent to which the magnitude of disease aggregation is related to the realized parameters of the Gibson model.

\section{MATERIALS AND METHODS}

Field plot. The garden was established with virus-tested plants (plants testing negative to infection by $\mathrm{HpLV}, \mathrm{HpMV}$, and ApMV by serological assay) of cultivar Victoria on a commercial hop farm at Bushy Park, Tasmania, Australia, in 1989. Plants were arranged in a pattern of 51 plants within each of 25 rows (total number of plants $=1,275$ ). Plants were separated by $1.8 \mathrm{~m}$ within rows and $2.1 \mathrm{~m}$ between rows. At approximately midseason (beginning of January), when plants had reached the top of the trellis framework $(5.5 \mathrm{~m})$, the plot was grazed by sheep, which removed all basal growth and lower laterals to a height of approximately $1 \mathrm{~m}$.

Serological assays for viruses. Six expanding leaves were collected randomly from all individual plants in early spring (first 2 weeks of September in each year) in 1996 and 1997. Subsamples (0.1 g) containing equal portions of all leaves were homogenized in $1.0 \mathrm{ml}$ of $0.01 \mathrm{M}$ phosphate-buffered saline $(\mathrm{pH}$ 7.4) containing polyvinylpyrrolidone (20 g/liter) and bovine serum albumin ( $2 \mathrm{~g} /$ liter), using a rotary leaf press. Sap extracts $(100 \mu \mathrm{l})$ were tested in duplicate by doubleantibody sandwich enzyme-linked immunosorbent assay (DAS-ELISA) (8) using polyclonal antisera to $\mathrm{HpLV}$, HpMV, Rose mosaic virus 3, and Chestnut mosaic virus. The latter two antisera were used to detect both the hop and intermediate serotypes of ApMV (5,37). Absorbance values at 405 $\mathrm{nm}$ were measured using a Titertek Multiskan Immunoplate Reader (Flow Laboratories, Helsinki, Finland). The appropriate positive, negative, and buffer controls for each virus were included on each plate. Samples with absorbance values greater than the mean of the negative control plus three times the standard deviation of the mean of the negative controls were considered virus infected (35).

Spatiotemporal analysis. Changes in plants infected by HpLV, HpMV, and ApMV (considering both the hop and intermediate serotype together) in the spatial lattice of the hop garden were analyzed using a spatiotemporal stochastic model (15). This involves a likelihood-based method to fit a spatially explicit model to the data using the Monte Carlo Markov Chain (MCMC) algorithm $(15,16)$.

The spatiotemporal model assumes that at a specific point in time, a susceptible plant acquires disease probabilistically with a rate that is controlled by a parameter vector, $\vec{a}\left(a_{1}, a_{2}\right)$ (18). The parameter $a_{1}$ quantifies the rate at which a susceptible plant becomes infected from sources unrelated to the location of other infected plants in the garden. An example of this would be increases in infected plants due to virus reservoirs outside the garden of interest. This has been called "background" infection rate by Gibson (15) and is, essentially, the monocyclic component of the epidemic. Because the likelihood calculations are overly sensitive to low values of $a_{1}$, this term is re-parameterized to $b=[\log (1$ $\left.\left.+a_{1}\right)\right]^{1 / 2}$ in the analysis and presentation. The lower bound for $b$ is 0 , reflecting no background infection; although there is no upper bound, a value of 3 is extremely large. At large $b$, background infection dominates disease increase over time.

The parameter $a_{2}$ quantifies the rate at which a susceptible plant becomes infected from sources within the garden. In the model formulation used here, the probability of a plant within the garden becoming infected from other plants within the same garden decreases as a power function of the distance $(r)$ between them, $r^{a_{2}}$. The parameter $a_{2}$ determines how the rate of infection, the so-called local infection rate (15), decreases with distance between plants. This term in the model is, essentially, representing the spatially explicit polycyclic component of the epidemic. The lower bound for $a_{2}$ is 0 ; as with $b$, there is no upper bound, but a value of 3 is very large. A small $a_{2}$ is indicative of a shallow dispersal gradient, meaning that disease spread can be over long distances; as $a_{2}$ increases, the dispersal gradient becomes steeper, indicating that disease spread is very local. At large $a_{2}$ (e.g., $\geq 3$ ), spread is largely of a nearest-neighbor interaction (i.e., spread is only to adjacent plants).

Large values of $b$ (or $a_{1}$ ), as well as the minimum $a_{2}(=0)$, are suggestive of random spatial patterns (15). Increasing $a_{2}$ results in more aggregated patterns of disease (17).

Parameter estimation procedures were identical to those previously described (15). In addition to point estimates of $b$ and $a_{2}$, which are the values of the parameters that result in the maximum value of the likelihood, the posterior parameter density is determined. The posterior density is used to ascertain the most probable values of the parameters given the data, and can be considered analogous to the confidence interval (or region) of a parameter estimate in classical (frequentist) statistics.

Spatial patterns of plants infected by HpLV, HpMV, and ApMV in both 1996 and 1997 were also analyzed by join-count statistics (40). A join-count statistic is a special case of a cross-product statistic (such as a correlation coefficient) for binary data; ordinary runs are onedimensional and first-order special cases of join-counts. Through this analysis, one can determine if neighboring plants (down rows, across rows, or diagonally) are more likely to have the same (or opposite) disease status compared with the situation when the infected plants are randomly positioned in the garden (40). For each virus and year, the observed and expected number of join-counts and the standard deviation of the expected value were determined (for a random pattern); the standard normal statistic $(Z)$ was calculated from these values. The join-counts and associated $Z$ statistics were determined for spatial lags of 1 (i.e., nearest neighbors) up to 15 in order to determine the scale of the clustering. A large negative value of $Z$ is indicative of aggregation. Calculations were performed with a generalization of the macro written by Gumpertz (21) for the Statistical Analysis System (SAS 8.0; SAS Institute, Cary, NC). Only results for the simultaneous within- and across-row comparison ("joins") are shown. This is often called the "Rook" comparison.

\section{RESULTS}

The spatial patterns of virus-infected plants in 1996 and 1997 are displayed in Figure $1 \mathrm{~A}$ to $\mathrm{C}$. The incidence of HpLVinfected plants was 65 and $88 \%$ in 1996 and 1997, respectively. Spread of HpMV in the garden was also rapid, increasing from $60 \%$ in 1996 to $77 \%$ only 1 year later. The incidence of plants infected by ApMV was 66 and 92\% in 1996 and 1997, respectively. 

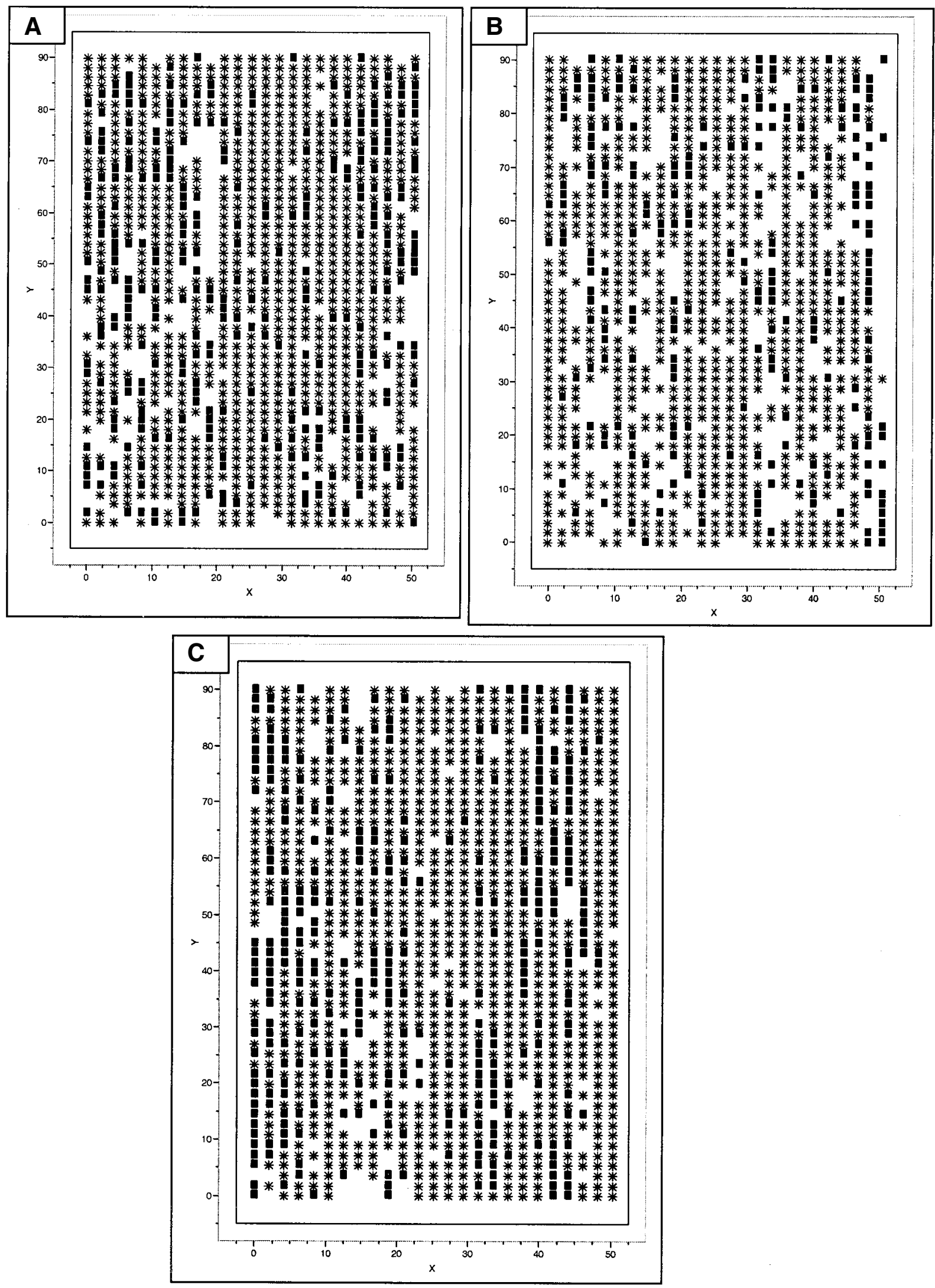

Fig. 1. Map of the spatial position of plants infected by A, Hop latent virus, B, Hop mosaic virus, and $\mathbf{C}$, Apple mosaic virus in an Australian hop garden (* indicates infected plants in 1996; indicates plants subsequently infected in 1997). Distance between plants (X,Y) is in meters. 
Contours of the posterior density of the parameter vector, $\vec{a}$, calculated with the MCMC procedure, are shown in Figure 2A to $\mathrm{C}$. The point estimate of $a_{2}$ was 3.5 for all three viruses, the largest value considered. This indicates a strong local spread of disease (i.e., between nearby plants). For the HpLV epidemic, there was strong evidence that $a_{2}$ was at least 2.0 based on the posterior density. For this epidemic, the point estimate of $b$ was 0.0 , and the posterior density indicated that $b$ was restricted to very low values (Fig. 2A). Thus, model results are consistent with disease increase being due primarily (or exclusively) by nearest-neighbor spread.

Similar results for $a_{2}$ were found for the HpMV epidemic (Fig. 2B). That is, the largest values of the posterior density were associated with large $a_{2}$ values, primarily values greater than 1 . However, unlike $\mathrm{HpLV}$, the point estimate of $b$ was 1.2 , and the posterior density indicated that the most probable value of $b$ was nonzero and between 1 and 2 (Fig. 2B). This is consistent with disease increase being due to both short-range spread between neighboring plants and background infections unrelated to the position of infected plants.

The point estimate of $b$ for the ApMV epidemic was 1.35 , similar to the estimate for the HpMV epidemic (Fig. 2C). As with HpMV, based on the posterior density of the parameter vector, the most probable value of $a_{2}$ (based on the 40th and higher percentiles of the posterior density) was greater than 1 , and the most probable value of $b$ was between 1 and 2. For ApMV, however, one could not reject the possibility that $b$ was 0 (or very small) and $a_{2}$ was small (e.g., 0.5) (Fig. 2C). A small $a_{2}$ is indicative of a relatively shallow dispersal gradient and corresponding long-range spread from infected plants.

Analyses of the join-count statistics in 1996 indicated that plants infected by HpLV, HpMV, and ApMV were significantly aggregated $(P<0.05)$ at one or more spatial lags (Fig. 3A). The $Z$ statistics generally declined with increasing spatial lag, but were significant for lags up to 8 , 15, and 6 for HpLV, HpMV, and ApMV, respectively. In 1997, there was significant aggregation for $\mathrm{HpLV}(P<0.05)$, HpMV $(P<0.05)$, and ApMV (at $P=0.055)$ for the first spatial lag (nearest neighbors). The $Z$ statistics also generally declined with increasing spatial lag, but were significant for lags up to 6 and 9 for HpLV and HpMV, respectively (Fig. 3B). The $Z$ statistics for ApMV in 1997 were larger (closer to 0) than for the other viruses and were generally not significant (except for the first-order lag).

\section{DISCUSSION}

Fitting a spatiotemporal stochastic model to data using the MCMC method of Gibson (15) was found to be useful for characterizing the temporal evolution of
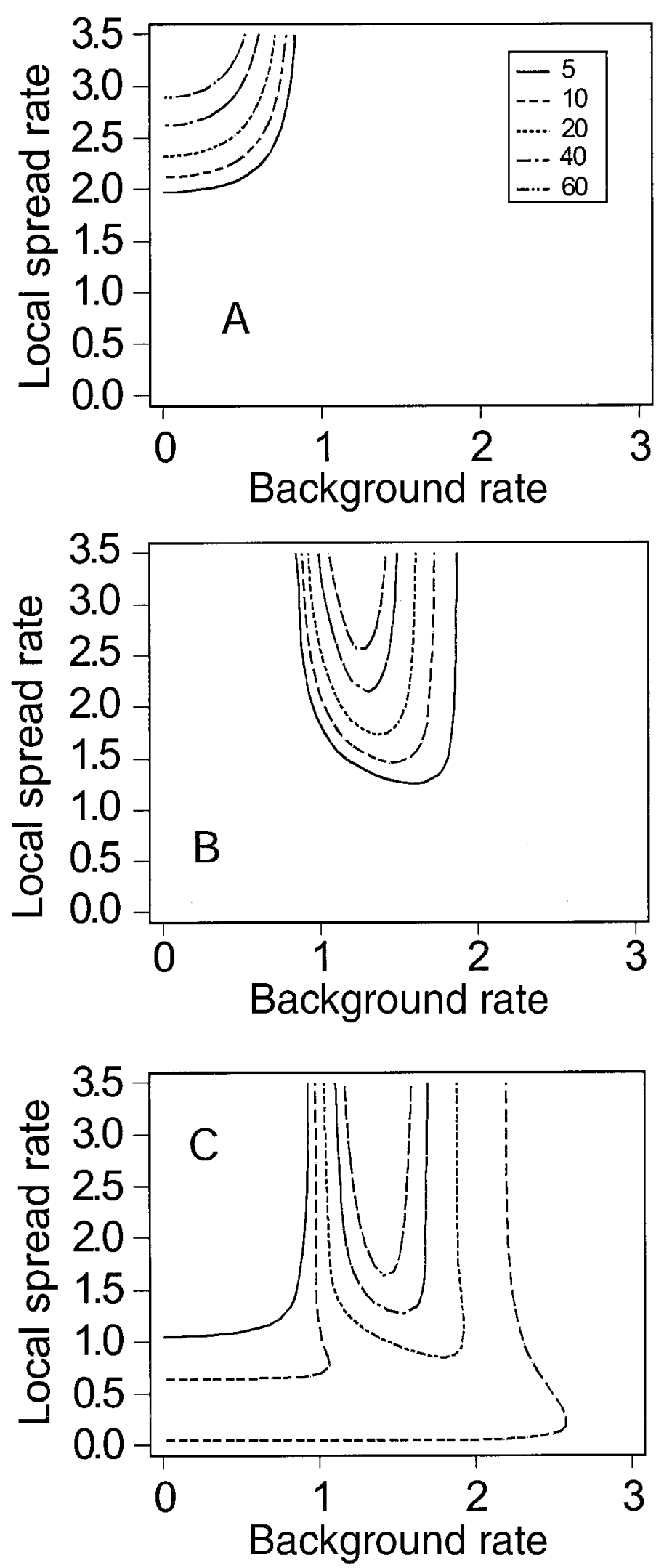

Fig. 2. Contour plots of designated percentiles of the posterior parameter density (i.e., normalized parameter likelihood $\mathrm{L}(\vec{a})$ ) of a spatiotemporal stochastic model fitted to spatially referenced data of the increase in hop plants in an Australian garden infected by A, Hop latent virus, B, Hop mosaic virus, and $\mathbf{C}$, Apple mosaic virus. Plots were obtained by estimating densities over a $21 \times 21$ grid of parameter values using the Monte Carlo Markov Chain method and interpolating between values. 
patterns of virus-infected plants in an Australian hop garden and for helping to elucidate mechanisms of disease spread. By combining these results with the results of the join-count analyses presented here and the previously reported radial correlation analyses (31), a fuller understanding of the late-epidemic hop virus epidemics is obtained.

Analyses indicated that the spread of HpLV over time was the most local of the three viruses studied. A very large point estimate of $a_{2}$, a point estimate of 0 for $b$, and a narrow posterior probability band around the point estimates (Fig. 2A), combined with sharp decreases in the magnitude of $Z$ statistics with increasing lags, revealed that the spread of $H p L V$ was very local and basically only to nearest neighbors (adjacent plants). The spatiotemporal spread of the other carlavirus, HpMV, was slightly different. Although there was strong evidence of very localized spread, based on $a_{2}$, some increase in dis-
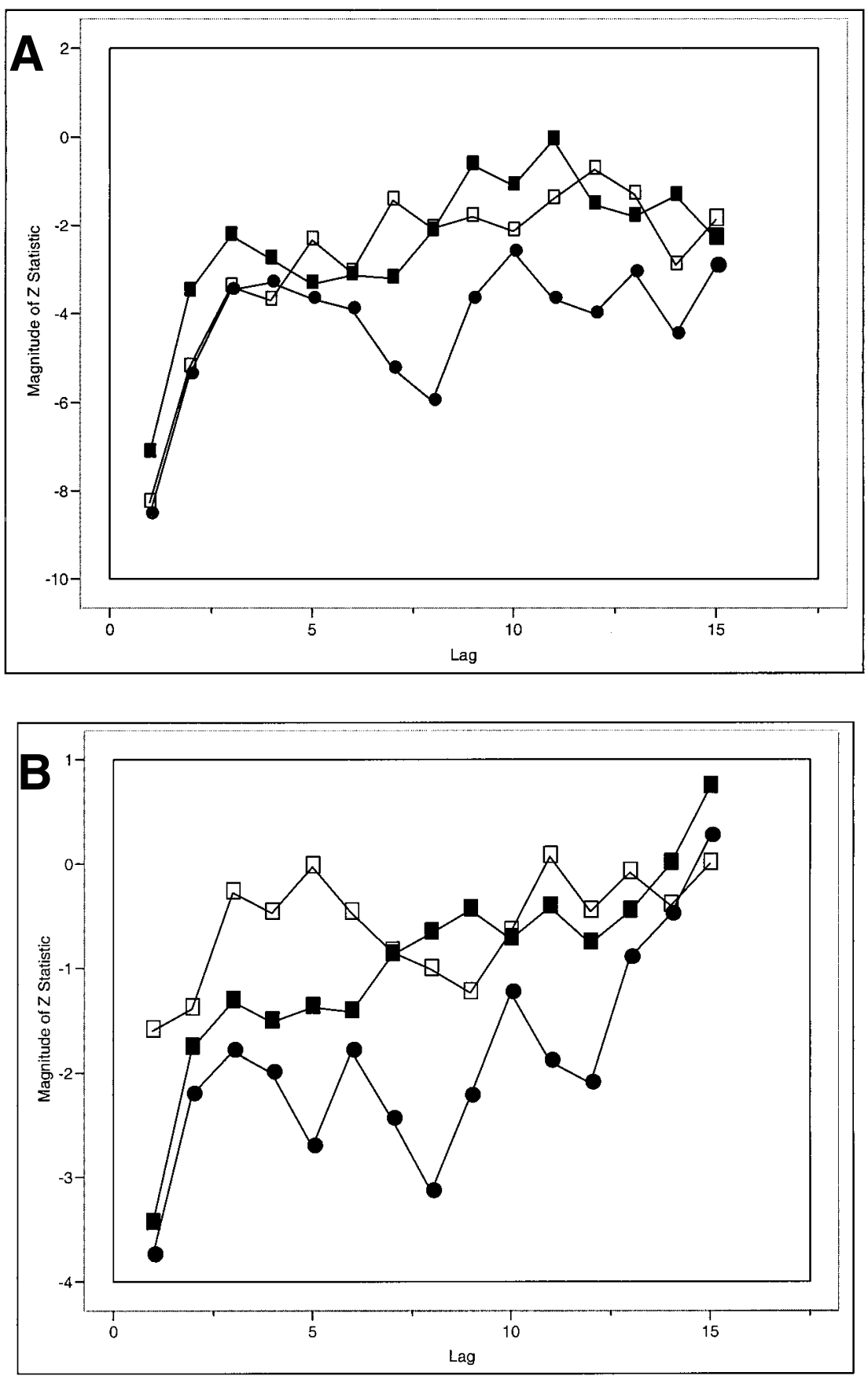

Fig. 3. Analysis of the spatial aggregation of hop plants infected by Hop latent virus (HpLV), Hop mosaic virus (HpMV), and Apple mosaic virus (ApMV) in a commercial 'Victoria' garden in A, 1996, and B, 1997, in an Australian hop garden by join-count statistics. This technique examined the significance of spatial aggregation down and across rows simultaneously (Rook case) up to 15 spatial lags. $Z$ statistics of $<-1.96$ indicated significant spatial aggregation for single tests $(\boldsymbol{\square}=\mathrm{HpLV}$; $=\mathrm{HpMV} ; \square=\mathrm{ApMV}$ ). eased plants that was unrelated to the location of the infected plants (background infection) was also revealed based on the nonzero value of the estimated $b$ (Fig. 2B). The patterns of spread for both HpLV and HpMV agree with the current knowledge on the aphid vectors involved in the transmission of the viruses. The only known aphid vector of HpLV, $P$. humuli $(1,28,29)$, is absent in Australia. The lack of evidence for background infection of $\mathrm{HpLV}$ over time supports the absence of this aphid vector. Introduction of HpLV into the crop is probably from infected planting material or volunteers within the garden. Transmission from these sources is likely to occur by mechanical transmission associated with mowing for basal growth (superfluous untrained basal shoots) control and/or contact between infected and healthy plants. The background infection by HpMV detected in these analyses also agrees with current knowledge, in that two aphid vectors of HpMV (M. euphorbiae and M. persicae) are present in Australian hop gardens $(2,4,28)$. This suggests that these aphid species are able to introduce HpMV into gardens from surrounding virus sources. The sole sources of both carlaviruses are infected hops in surrounding gardens $(1,2)$. However, a substantial fraction of transmission was local and shortrange, which suggests mechanical transmission associated with cultural operations or the movement of alatae or apterous vectors only between neighboring infected and healthy plants along rows. Because the join-count and radial correlation statistics for $\mathrm{HpLV}$ and $\mathrm{HpMV}$ at each time were similar (Fig. 3; 31), the observed pattern of diseased plants appears to be most determined by the strong local spread of disease.

Strong local spread from infected plants to neighbors, coupled with some background infection from outside virus sources, was also suggested for ApMV based on the estimates of $a_{2}$ and $b$. However, because contours of the posterior probability density were skewed, there was more ambiguity in the likely parameter values, and the possibility of longerdistance spread $\left(a_{2} \approx 0.8\right)$ coupled with minor background infection (small $b$ ) cannot be rejected. Gottwald et al. (18) also found some cases of parameter ambiguity for analyzed virus epidemics of citrus. The join-count statistics for 1997 were lower than for the other viruses (Fig. 3), indicating less evidence of aggregation, consistent with a low value for $a_{2}(15)$. The high incidence of ApMV-infected plants may have affected the significance testing of the joincounts for this year $(21,40)$, and also contributed to the ambiguity in parameter values because there were fewer opportunities for disease to spread to disease-free plants. Previous studies of ApMV transmission between hop plants have suggested that transmission is solely mechanical by 
contact between infected and healthy plants, simulated pruning, or root grafting $(11,30)$. In the field, preventing contact between infected and healthy plants early in the season reduced the transmission of ApMV to healthy plants by half (30). This suggested that while ApMV spread may occur on machinery through cultural operations such as mowing, contact between infected and healthy plants strongly influences the success of transmission. While the role of root grafting in virus transmission has been demonstrated in glasshouse trials and the presence of root grafts in Australian hop gardens suggested by glyphosate injections, the role of root grafting in virus transmission in the field is unclear (30). The manner by which ApMV is introduced into gardens remains unknown. The planting of infected material or the movement of ApMV on machinery between adjacent gardens may explain introductions. However, the position of ApMVinfected plants soon after garden establishment is not biased toward garden edges (unpublished data), suggesting that introductions are not due solely to mechanical transmission. Another possibility is the role of virus-infected pollen and mechanical transmission action of insects, similar to that described in Prunus spp. (19,20). While 'Victoria' and the majority of other Australian-bred hop cultivars are triploid, male diploids may be planted in the triploid gardens or in the vicinity. Furthermore, hop pollen gathered from male plants infected by ApMV in the UK was also infected by ApMV (36). However, the role of infected pollen in the transmission of ApMV between hop plants remains unclear.

Estimation of parameters of spatiotemporal models using MCMC was previously shown to be valuable for comparing epidemics in different locations, comparing epidemics of a single virus with different vectors, and evaluating possible control strategies $(15,16,18)$. Here we found that spatiotemporal analysis of three different viruses in the same field was useful in developing a more comprehensive knowledge on how these viruses are transmitted in an Australian hop garden. These models suggest the management of HpLV may rely primarily upon the use of virus-free material for garden establishment, where HpMV and ApMV may be more difficult to manage because of the likely involvement of background sources. Further investigations will concentrate on determining the role of mechanical transmission in the epidemiology of the HpMV. This will assist in judging whether changes in basal growth control methods or whether local spread is due to apterous and/or alatae aphid activity within the garden. Further investigations into the epidemiology of ApMV will concentrate on the means, if any, by which this virus is transmitted over longer distances. Changes in basal growth control, such as the use of desiccant herbicides instead of mowing early in the season, will minimize contact between infected and healthy plants and reduce local spread of all three viruses $(30,31)$. However, infection by HpMV and, to a lesser extent, by ApMV may also be minimized by the use of virus-free planting material and the selection of sites isolated from established hop gardens. If gardens cannot be geographically isolated from established gardens, depending upon the rate of virus reinfection into the garden, roguing of infected plants may be an effective management tool, assuming the effects of infection on yield are significant and the rate of ingress into the garden is sufficiently slow.

\section{ACKNOWLEDGMENTS}

We thank L. Sherriff and G. Leggett, Australian Hop Marketers, and F. Hay and C. Wilson, Tasmanian Institute of Agricultural Research, for constructive discussion. This project was supported by funds from the Australian Research Council and Australian Hop Marketers.

\section{LITERATURE CITED}

1. Adams, A. N., and Barbara, D. J. 1980. Host range, purification and some properties of hop mosaic virus. Ann. Appl. Biol. 96:201-208.

2. Adams, A. N., and Barbara, D. J. 1982. Host range, purification and some properties of two carlaviruses from hop (Humulus lupulus L.): Hop latent and American hop latent. Ann. Appl. Biol. 101:483-494.

3. Adams, A. N., Barbara, D. J., and Blake, V. S. A. 1983. Viruses and virus diseases of hops Carlaviruses. Rep. East Malling Res. Stn. 1982:82-89.

4. Adams, A. N., Barbara, D. J., Clark, M. F., Manwell, W. F., and Thresh, J. M. 1979. Virus diseases of hop. Rep. E. Malling Res. Stn. 1978:102-103.

5. Barbara, D. J., Clark, M. F., Thresh, J. M., and Casper, R. 1978. Rapid detection and serotyping of prunus necrotic ringspot virus in perennial crops by enzyme-linked immunosorbent assay. Ann. Appl. Biol. 90:395-399.

6. Cameron, R. R., Milbraith, J. A., and Tate, L. A. 1973. Pollen transmission of prunus necrotic ringspot in prune and sour cherry orchards. Plant Dis. Rep. 57:241-243.

7. Chambers, D. A., Highnett, R. C., Carder, J. H., Marks, M. J., Adams, A. N., and Blake, V. S. A. 1986. Diseases of hop. Rep. East Malling Res. Stn. 1985:137-140.

8. Clark, M. F., and Adams, A. N. 1977. Characteristics of the microplate method of enzymelinked immunosorbent assay for the detection of plant viruses. J. Gen. Virol. 34:475-483.

9. Cole, A., Mink, G. I., and Regev, S. 1982. Location of prunus necrotic ringspot virus on pollen grains from infected almond and cherry trees. Phytopathology 72:1542-1545.

10. Eppler, A. 1994. Ecology of aphids on hops and its significance to spread of hop viruses. Z. Pflanzenkr. Pflanzenschutz 102:2-15.

11. Eppler, A., and Dahdahbiglou, R. 1991. Experiments on the non-vectorial transmission of PNRV in hops. Med. Fac. Landbouww. Rijksuniv. Gent. 56:577-587.

12. Fritzsche, R., and Kegler, H. 1968. Nematoden als vectoren von viruskrankteiten der obstgehotze. Tag. Ber. D. Akad. Land. Wiss. DDR. 97:289-295

13. George, J. A., and Davidson, T. R. 1963. Pollen transmission of sour cherry yellows viruses from tree to tree. Can J. Plant Sci. 43:276-288.
14. George, J. A., and Davidson, T. R. 1964 Further evidence of pollen transmission of necrotic ringspot and sour cherry yellows viruses in sour cherry. Can. J. Plant Sci. 44:383384.

15. Gibson, G. J. 1997. Investigating mechanisms of spatiotemporal epidemic spread using stochastic models. Phytopathology 87:139-146.

16. Gibson, G. J. 1997. Markov chain monte carlo methods for fitting spatiotemporal epidemic stochastic models in plant pathology. Appl. Stat. 46:215-233.

17. Gibson, G. J., and Austin, E. J. 1986. Fitting and testing spatio-temporal stochastic models with applications in plant epidemiology. Plant Pathol. 45:172-184.

18. Gottwald, T. R., Gibson, G. J., Garnsey, S. M. and Irey, M. 1999. Examination of the effect of aphid vector population composition on the spatial dynamics of citrus tristeza virus spread by stochastic modeling. Phytopathology 89:603-608.

19. Greber, R. S., Klose, M. J., Milne, R. S., and Teakle, D. S. 1991. Transmission of prunus necrotic ringspot virus using plum pollen and thrips. Ann. Appl. Biol. 118:589-593.

20. Greber, R. S., Teakle, D. S., and Mink, G. I. 1992. Thrips-facilitated transmission of prune dwarf and prunus necrotic ringspot viruses from cherry pollen to cucumber. Plant Dis. 76:1039-1041.

21. Gumpertz, M. L. 1997. Testing binary response variables for spatial autocorrelation. Pages 78-84 in: Exercises in Plant Disease Epidemiology. L. J. Francl and D. A. Neher, eds. American Phytopathological Society, St. Paul, MN.

22. Hay, F. S., Close, R. C., Fletcher, J. D., and Ashby, J. W. 1992. Incidence and spread of viruses in hop (Humulus lupulus L.) in New Zealand. N.Z. J. Crop Hortic. Sci. 20:319327.

23. Hughes, G., McRoberts, N., Madden, L. V., and Nelson, S. C. 1997. Validating mathematical models of plant disease progress in space and time. IMA J. Mathematics Appl. Med. Biol. 14:85-112.

24. Madden, L. V., and Hughes, G. 1995. Plant disease incidence: Distributions, heterogeneity, and temporal analysis. Annu. Rev. Phytopathol. 33:529-564.

25. Madden, L. V., Nault, L. R., Murral, D. J., and Apelt, M. R. 1995. Spatial pattern analysis of the incidence of aster yellows disease in lettuce. Res. Population Ecol. 37:279-289.

26. Munro, D. 1987. Viruses infecting hop, $\mathrm{Hu}$ mulus lupulus, in Australia. Aust. J. Agric. Res. 38:83-90.

27. Munro, D. 1989. Spread of hop latent and hop mosaic virus in the absence of Phorodon humuli. Pages 109-112 in: Proc. Int. Workshop Hop Virus Dis. Giessen.

28. Paine, J. 1953. Insect vector studies with mosaic and other virus diseases of the hop Rep. E. Malling Res. Stn. 1952:120-123.

29. Paine, J., and Legg, J. T. 1953. Transmission of hop mosaic by Phorodon humuli (Shranck). Nature 171:263-264.

30. Pethybridge, S. J. 2000. Epidemiology of Viruses Infecting Hop in Australia. Ph.D. thesis. University of Tasmania, Hobart, Tasmania, Australia.

31. Pethybridge, S. J., Wilson, C. R., Ferrandino, F. J., and Leggett, G. W. 2000. Spatial analyses of viral epidemics in Australian hop gardens: Implications for mechanisms of spread. Plant Dis. 84:513-515.

32. Pethybridge, S. J., Wilson, C. R., Hay, F. S., Leggett, G. W., and Sherriff, L. J. 2002. Effect of viruses on agronomic and brewing characteristics of four hop (Humulus lupulus) cultivars in Australia. Ann. Appl. Biol. 140:97-105.

33. Pethybridge, S. J., Wilson, C. R., Sherriff, L. 
J., Leggett, G. W., and Munro, D. 2001. Virus incidence in Australian hop (Humulus lupulus L.) gardens and cultivar differences in susceptibility to infection. Aust. J. Agric. Res. 51:685-689.

34. Proesler, G. 1968. Ubertragungsverusche mit dem lateten prunus-virus und der gallmibe Vasates fockeui. Nal. Phytopathol. Z. 63:1-9.

35. Sutula, C. L., Gillett, J. M., Morrissey, S. M., and Ramsdell, D. C. 1986. Interpreting ELISA data and establishing the positive-negative threshold. Plant Dis. 70:722-726.

36. Thresh, J. M. 1980. Virus diseases of hop Prunus necrotic ringspot virus (NRSV). Rep. East Malling Res. Stn. 1979:103.

37. Thresh, J. M., Adams, A. N., Barbara, D. J., and Clark, M. F. 1977. The detection of three viruses of hop (Humulus lupulus) by enzymelinked immunosorbent assay (ELISA). Ann. Appl. Biol. 87:57-65.

38. Thresh, J. M., Barbara, D. J., and Ormerod, P. J. 1988. The incidence and spread of prunus necrotic ringspot virus in English hop plantings. Pages 71-82 in: Proc. Int. Workshop Hop Virus Dis. Giessen.

39. Thresh, J. M., and Ormerod, P. J. 1973. Virus diseases of hop - spread of prunus necrotic ringspot virus in hop. Rep. East Malling Res. Stn. 1972:163-164.

40. Upton, G., and Fingleton, B. 1985. Spatial data analysis by example. Vol. 1, Point Pattern and Quantitative Data. John Wiley \& Sons, Chichester. 